\title{
Serum protein complex profiling reveals heterogeneity of Balanced constitutional population in traditional Chinese medicine through blue native polyacrylamide gel electrophoresis
}

\author{
Fei Tan ${ }^{1,2,3}$, Tao Zhang ${ }^{2}$, Xinyan Chen ${ }^{1}$, Tingting Song ${ }^{2}$, Jiamin Yuan ${ }^{1}$, Chen Sun ${ }^{1}$, Fuping Xu ${ }^{1}$, \\ Yanchang $\mathrm{Li}^{2}$, Lei Chang ${ }^{2}$, Fuqiang Wang ${ }^{2}$, Chen Shao ${ }^{2}$, Weimin $\mathrm{Zhu}^{2}$, Ping $\mathrm{Xu}^{2,3}$, Zhimin Yang ${ }^{1,3}$ \\ ${ }^{1}$ State Key Laboratory of Dampness Syndrome of Chinese Medicine, The Second Affiliated Hospital of Guangzhou University of Chinese Medicine, \\ Guangzhou, China; ${ }^{2}$ State Key Laboratory of Proteomics, Beijing Proteome Research Center, National Center for Protein Sciences (Beijing), \\ Research Unit of Proteomics \& Research and Development of New Drug of Chinese Academy of Medical Sciences, Institute of Lifeomics, Beijing, \\ China; ${ }^{3}$ Guangzhou University of Chinese Medicine, Second Clinical Medicine Collage, Guangzhou Higher Education Mega Center, Guangzhou, \\ China \\ Contributions: (I) Conception and design: Z Yang, P Xu; (II) Administrative support: L Chang, X Chen, F Wang, Y Li; (III) Provision of study \\ materials or patients: F Tan, X Chen, J Yuan, C Sun, F Xu; (IV) Collection and assembly of data: F Tan, X Chen; (V) Data analysis and interpretation: \\ F Tan, T Zhang, T Song; (VI) Manuscript writing: All authors; (VII) Final approval of manuscript: All authors. \\ Correspondence to: Zhimin Yang. State Key Laboratory of Dampness Syndrome of Chinese Medicine, The Second Affiliated Hospital of Guangzhou \\ University of Chinese Medicine. No. 111 Dade Road, Guangzhou 510120, China. Email: yangyo@vip.tom.com; Ping Xu. State Key Laboratory \\ of Proteomics, Beijing Proteome Research Center, National Center for Protein Sciences (Beijing), Research Unit of Proteomics \& Research and \\ Development of New Drug of Chinese Academy of Medical Sciences, Institute of Lifeomics, Beijing 102206, China. Email: xuping@mail.ncpsb.org.
}

Background: Pulse-taking is widely used for diagnosis and treatment in traditional Chinese medicine (TCM), and protein complexes in serum perform various biological functions. The Balanced constitution is one of the major constitutions in TCM, people with Balanced constitution can also share some common characteristics with unbalanced constitution types.

Methods: Blue native polyacrylamide gel electrophoresis (BN-PAGE) was applied to the serum of 25 people with balanced constitutions. The patterns of the protein complexes could be recognized according to the number, molecular weight, and intensity of the gel bands. All of the individual bands from these patterns were cut and in-gel-digested with trypsin, followed by liquid chromatography-mass spectrometry/mass spectrometry (LC-MS/MS) analysis for protein identification and biological function analysis.

Results: The protein complex patterns were roughly categorized as type A and B with high stability and reproducibility, and there were 15 and 16 gel bands in type A and type B, respectively. Among the 25 serum samples, 14 belonged to type A, and 11 belonged to type B. High-abundance proteins significantly decreased from $99 \%$ to $44 \%$ after BN-PAGE separation. The unique proteins in type A were mainly related to lipid metabolism, while the unique proteins in type B were involved in biological processes related to immune response and inflammatory regulation. The Qi-deficiency constitution converted score of type A was higher than that of type B, while the Damp-heat constitution converted score of type A was lower than that of type B. Conclusions: Our study provided an objective reference for diagnosis and prognosis, which might lay a foundation for establishing the characteristic protein complex spectra of all of the TCM constitutions.

Keywords: Traditional Chinese medicine (TCM); Balanced constitution; blue native PAGE; protein complex

Submitted Jan 28, 2020. Accepted for publication Jul 31, 2020.

doi: 10.21037/apm-20-290

View this article at: http://dx.doi.org/10.21037/apm-20-290 


\section{Introduction}

The individual differences across people is a topic that has continually attracted interest in clinical medicine. Researchers have put great effort into exploring how modern evolutionary psychology and emotional regulation impacts individual differences and personality $(1,2)$. When it comes to traditional or modern Chinese medicine, it is critical to assess the human constitution in order to distinguish individual differences (3).

Traditional Chinese medicine (TCM) constitution refers to stable morphological features, physiological functions, and psychological states, which emerge from the dichotomy of nature $v s$. nurture lifestyle influences, and can be conceptually compared to the concept of personalized medicine (4). TCM constitution theory classifies individual constitutions into nine types based on the Chinese medical theoretical framework, with eight of these being unbalanced constitutional types. The theory is used to guide the prevention, diagnosis, and treatment of diseases, along with rehabilitation and health. The Classification and Determination of Constitution in TCM, published by the China Association of TCM, was established by TCM physicians after 30 years of research, and has been tested by clinical experts and epidemiologists. It is an interdisciplinary approach that integrates epidemiology, immunology, molecular biology, genetics, and mathematical statistics into its analysis (5). According to TCM constitution theory, strategies for the prevention and treatment of disease should be always based on the individual's constitution, and the eight unbalanced constitutions are usually more vulnerable to disease and require special attention. Conversely, the medical attention given to people with Balanced constitution is often lacking, as Balanced constitution does not necessarily ensure an exemption from all sicknesses (6-10).

Indeed, Balanced constitution does not automatically equate to a perfectly healthy condition. When people with Balanced constitution fall sick, the disease will develop according to the characteristics of their constitution (11). In previous studies of the relationship between TCM constitutions and various diseases, such as tumors (12), metabolic diseases $(13,14)$, immune disorders, and emotional disorders $(15,16)$, people with the balanced constitution have accounted for a certain proportion of those with these diseases. In TCM acupuncture treatment, there are obvious differences in the sensation propagated along the meridians among people with different constitutions $(17,18)$. From a clinical perspective, many people with Balanced constitution are in a suboptimal state of health, and specific medical intervention is needed. The individual differences and the heterogeneity of the population may help to explain the occurrence of diseases in the segment of the population with Balanced constitution.

Blood can be a window through which we can peer into a person's health or illness. Blood analysis is commonly performed to detect disease and determine if the organs are functional (19). In TCM theory, blood is the basis of physiological activities, and thus also fundamentally informs pulse diagnosis. The biological mechanism behind pulse diagnosis has been verified by modern medicine $(20,21)$. Serum contains a variety of proteins that respond to the pathogenesis of disease, which makes it an engaging subject for clinical research (22). The rapid development of serum proteomics has led to the discovery of more single-molecular biomarkers; however, the diagnostic accuracy of these markers is not yet satisfactory (23). As the cornerstone of biological processes, protein complexes perform a vast array of biological functions (24), and the proteins that compose those complexes could serve as indicators of physical status. Blue native polyacrylamide gel electrophoresis (BNPAGE) combined with mass spectrometry-based proteomic technologies can be used to isolate and detect native proteins and to identify physiological protein-protein interactions in serum (25). This method can also remove some highly abundant proteins from the serum. It may be worthwhile to explore the biological basis of TCM constitution classification by establishing the serum protein profile of different TCM constitutions.

As a cutting-edge technology for TCM classification, proteomics was used to explore the characteristics of individuals with Balanced constitution (26,27). In our study, the protein profiles of 25 healthy volunteers with balanced constitutions were classified into two major patterns. Furthermore, the two patterns of the balanced constitution were found to be associated with TCM unbalanced constitution convert scores, suggesting a transition from Balanced constitution to an unbalanced constitution. Our results represent a valuable approach for investigating individual differences and provide new insights into the categories of TCM classification.

\section{Methods}

\section{Serum samples}

Volunteers for our study underwent a comprehensive health 
examination at the Guangdong Provincial Traditional Chinese Medical Hospital, and serum samples were collected afterwards. All of the participants met the classification criteria of the balanced constitution with no experience of disease or medical treatment records within 2 months before their visit. The body constitution status of all the participants was evaluated using the TCM Physical Constitution Scale (4). The main method of measurement was a scientific symptom questionnaire. It is worth noting that all the volunteers came from the same village in Foshan City of the Guangdong Province. They shared a homogeneous genetic background, living environment, and eating habits, which made them an ideal population for this study.

The blood samples from these volunteers were also subjected to blood biochemistry measurements. The serum samples were managed by the Biological Resource Center of the Guangdong Provincial Hospital of Chinese Medicine. The study was approved by the Animal Ethics Committee of the Guangdong Provincial Hospital of Chinese Medicine (B2017-150-01) and was performed in accordance with the tenets of the Declaration of Helsinki (as revised in 2013). Informed consent was given by all participants.

\section{Classification of TCM constitution type}

The constitution type of participants was evaluated using the TCM Constitution Scale (4). The survey consists of 60 questions, and there are 5 options for each question (not all, few, sometimes, often, always), corresponding to 1-5 points. There were nine subscales used to assess the nine TCM constitution types individually, including balanced constitution, qi-deficiency constitution, yang-deficiency constitution, yin-deficiency constitution, phlegm-damp constitution, damp-heat constitution, blood-stagnation constitution, qi-stagnation constitution, and inherited special constitution. Firs, we calculated the score by totaling the scores of each subscale. Then, the constitution convert scores of each subscale were calculated by applying the following formula: (original score - the number of questions)/(the number of questions $\times 4$ ) $\times 100$. If the constitution convert scores of the balanced constitution was $>60$ or the constitution convert scores of the eight unbalanced constitutions were $<40$ points, Balanced constitution was claimed. If the score of any constitution subscale was $\geq 40$ points, they were deemed to have unbalanced constitutions.

\section{BN-PAGE analysis of the serum sample}

Serum protein complexes were resolved and displayed by BN-PAGE as described previously, with some modification (25). Briefly, $2.5 \mu \mathrm{L}$ of serum sample was mixed with $7.5 \mu \mathrm{L}$ of sample loading buffer $(31.25 \mathrm{mM}$ Tris- $\mathrm{HCl}, 12.5 \%$ glycerol, $0.5 \%$ bromophenol blue. $\mathrm{pH} 7.5)$. The samples were run on a $3.2 \%$ stacking gel followed by $5-11 \%(\mathrm{w} / \mathrm{v})$ (acrylamide/bisacrylamide =37:1) gradient acrylamide gel $[150 \mathrm{mM}$ Bis-Tris, $200 \mathrm{mM}$ 6-Amino acetic acid ( $\mathrm{pH} 7.4)$ ] containing 70\% glycerol to separate the protein complexes in the serum. Electrophoresis was performed at $100 \mathrm{~V}$ for $1 \mathrm{~h}$ at room temperature, followed by $300 \mathrm{~V}$ for $7 \mathrm{~h}$ at $4{ }^{\circ} \mathrm{C}$. After electrophoresis, the gel was stained with Coomassie Brilliant Blue G-250. The image of the gel was scanned with an HP Scanjet G4050 (Hewlett-Packard, Inc., Palo Alto, CA, USA). The bands of the serum protein complexes were identified by ImageJ software (National Institutes of Health, USA; https://imagej.nih.gov/ij/ download.html).

\section{Protein complex pattern analysis}

The same amount of prestained molecular weight markers was used as a reference for each individual gel. Gels were manually aligned based on the molecular weight of the markers. Each individual band was labeled with a number based on its molecular weight from the top to the bottom. Image J was used for image processing; the gel image was converted into an array of pixels, in which the intensity of the band was represented by peaks. The abundance value of a band was calculated by the sum of areas under the peak. The relative abundance and distinguishable bands were selected by cluster analysis to represent the patterns of protein complexes from each individual serum sample. Consensus clustering was performed with $\mathrm{MeV}$ (Multi Experiment View) software, using the hierarchical clustering method with Pearson's correlation coefficient.

\section{MS sample preparation}

The distinguishable representative gel bands were sliced from the BN-PAGE gels for in-gel trypsin digestion as described previously (28). The tryptic peptides were dried under a vacuum for further analysis. 
Liquid chromatography-mass spectrometry/mass spectrometry (LC-MS/MS) analysis

Peptides were analyzed using an ultra-performance LCMS/MS platform of a hybrid LTQ-Orbitrap Velos mass spectrometer (Thermo Fisher Scientific, Inc., San Jose, CA, USA) equipped with a Waters nanoACQUITY ultraperformance liquid chromatography system (Waters Corporation, Inc., Milford, MA, USA). Each sample was reconstituted with $10 \mu \mathrm{L}$ of $0.1 \%(\mathrm{v} / \mathrm{v})$ formic acid and $1 \%(\mathrm{v} / \mathrm{v})$ acetonitrile in water for subsequent analysis. The liquid chromatography separation was performed on an in-house packed capillary column $(75 \mu \mathrm{m}$ inner diameter $\times 15 \mathrm{~cm}$ length) with 3- $\mu \mathrm{m}$ C18 reverse-phase fused silica column (Michrom Bioresources, Inc., Auburn, CA, USA). The samples were loaded into the column by an autosampler and eluted with a 30-min gradient covering $0-100 \%$ of phase $\mathrm{B}$ (phase $\mathrm{B}, 0.1 \% \mathrm{FA}$ in $\mathrm{ACN}$; phase $\mathrm{A}, 0.1 \% \mathrm{FA}$ $+2 \% \mathrm{ACN}$ in water) with a flow rate of $0.3 \mu \mathrm{L} / \mathrm{min}$. Eluting peptides were analyzed using an LTQ-Orbitrap Velos mass spectrometer. The full scan was performed within $\mathrm{m} / \mathrm{z}$ $300-1,600$ with a resolution of 30,000 at $\mathrm{m} / \mathrm{z} 400$. The automatic gain control was set to $1 \times 10^{6}$, and the maximum injection time was $150 \mathrm{~ms}$. After a full scan, the top 20 most abundant ions were selected for MS/MS analysis under $35 \%$ normalized collision energy (NCE) in the linear ion trap (LTQ). The precursor isolation window was set to 2, and the dynamic exclusion time was set to 35 seconds.

\section{Bioinformatics analysis of identified proteins of gel bands}

The acquired raw files were searched by MaxQuant software suite (version 1.5.6.0, Martinsried, Germany) against the UniProt human reference protein database (version March, 2017). MS search parameters consisted of full tryptic restriction, fixed modification of cysteine carbamidomethylation, and variable modifications of methionine oxidation. The maximum false discovery rates (FDR) for peptide and protein identification were specified as 0.01 . Gene ontology (GO) annotation and pathway analysis were performed using the DAVID website (version 6.8, https://david.ncifcrf.gov/home.jsp) $(29,30)$.

\section{Statistical analysis}

Statistical analysis was performed using GraphPad Prism software (v6.01, GraphPad software, Inc., San Diego, CA, USA) and SPSS V26.0 (IBM Corporation, Armonk, NY,
USA). Variables accounted for in all our analyses. Groupwise comparisons done with chi-square test for categorical variables and ANOVA test for discrete variables. $\mathrm{P}$ values less than 0.05 were considered significant. Figures were arranged for publishing using Photoshop CS6 (Adobe Systems, Inc., San Jose, CA, USA).

\section{Results}

\section{High reproducibility of human serum protein complex patterns resolved by blue native PAGE}

BN-PAGE was applied to detect the functional protein complex in serum samples. To measure the reproducibility of our BN-PAGE, protein electrophoresis was carried out with four technical replicates. Coomassie blue staining showed multiple distinguishable gel bands on each technical replica, ranging from 146 to $1,048 \mathrm{kDa}$ (Figure 1A). All of the bands in the same lane with varied molecular weight and intensity formed specific protein complexes that might have represented the identity of the individual serum sample. The patterns of the bands from all the four replicates were almost identical, indicating the high reproducibility of our BN-PAGE.

To further verify the reproducibility of BN-PAGE, the technical replicas were analyzed 3 days in a row. The same distinguishable gel bands, ranging from 146 to $1,048 \mathrm{kDa}$, were observed on each lane in each run (Figure 1B). The overall intensity of the entire lane on different gels varied because of the different staining and destaining times. However, the relative intensity of the gel bands compared to their own molecular weight markers remained the same, indicating the amount of the samples was equivalent. The gel patterns of the protein complexes from all technical replicates of the human serum samples were almost identical which confirmed the high reproducibility of the BN-PAGE technology.

\section{Varied protein complex patterns identified from the people with balanced constitutions}

Pulse diagnosis is a traditional Chinese medical technique used in the evaluation of health conditions and disease diagnosis. To understand the biological basis of this diagnostic technique, BN-PAGE was applied to evaluate the protein complex profiles of serum samples from 25 people with Balanced constitution according to pulse diagnosis.

BN-PAGE was used to isolate protein complexes from 
A

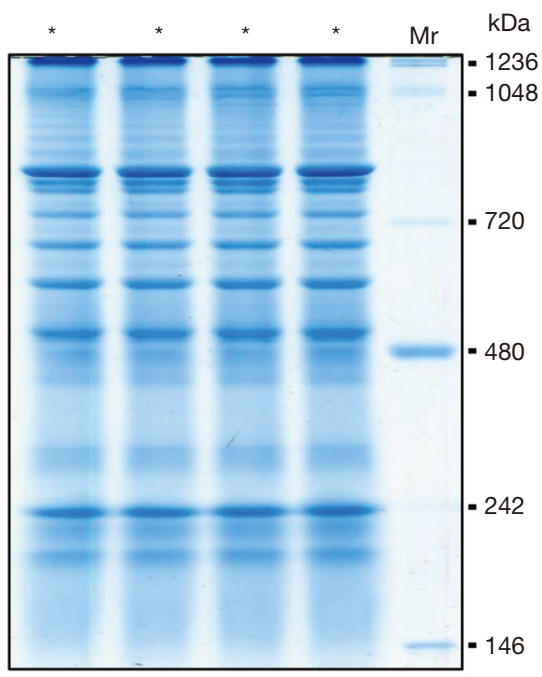

B

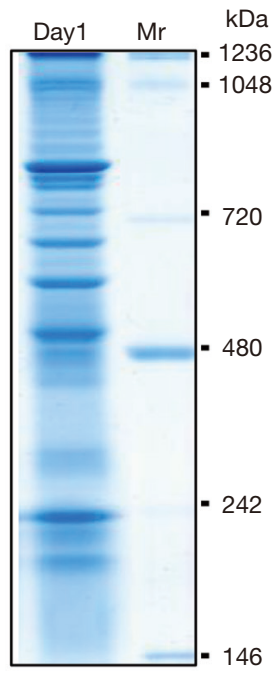

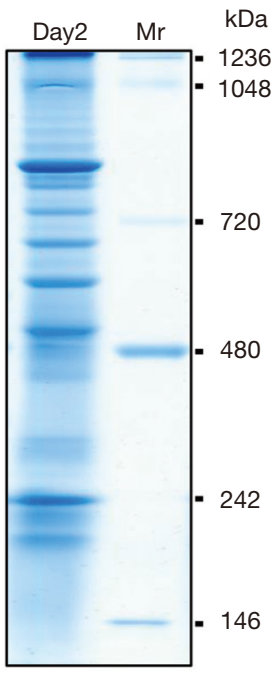

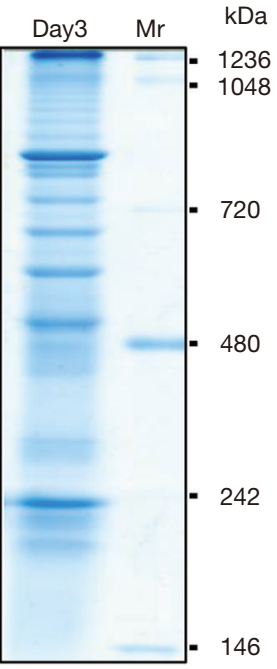

Figure 1 High reproducibility of human serum protein complex patterns detected by BN-PAGE. Mr and kDa indicate protein marker and kilodalton, respectively. (A) The gel pattern of serum samples loaded in multiple lanes was consistent. "*" represents the same sample that was repeatedly loaded, which is also shown in Figure $2 A$ as \#6. (B) The gel pattern of the same serum loaded at different times remained unchanged.

25 serum samples (Figure $2 A$ ). Image J software was used to identify the characteristics of the protein profile. The gel image was converted to gray color in order to be recognized by ImageJ. A marker ladder was used to determine the molecular weight. The number of gel bands was counted, and the intensity of each band was quantified. Additionally, the clustering method was used to identify the protein complex patterns of the 25 samples. The intensity and molecular weight of each gel band were used to generate the cluster (Figure 2B). The results clearly showed two major patterns, type $A$ and type $B$, and three minor patterns.

In type $\mathrm{A}$, there were 15 bands ranging from 146 to 1,236 $\mathrm{kDa}$, which were labeled $\mathrm{A} 1-\mathrm{A} 15$, respectively. We also noticed a subtype of type A, which was named A', whose protein complex pattern was very similar to that of type A except there was an additional band located at $242 \mathrm{kDa}$. This additional band was set as A12', as its molecular weight was between $\mathrm{A} 12$ and A13. There were 16 bands in type B, which were labeled B1-B16. Similarly to type A, type B contained subtypes B' and B". Compared with type B, type B' had two additional bands. B10' and B13', while type B" had two additional bands (B13" and B14') instead of B14 (Figure 2C).

Notably, band A1-15 appeared in all 14 type A samples, in which 13 samples belonged to type A, and 1 sample belonged to type A'. There were 8,2 , and 1 samples in type B, B', and B", respectively (Figure $2 B$ ). The main characteristics of the 25 volunteers in type $A$ and type $B$ are shown in Table S1. No significant differences were found in gender, age, body mass index (BMI), heart rate (HR), systolic blood pressure (SBP), diastolic blood pressure (DBP), fasting plasma glucose (FPG), total cholesterol (TC), total triglyceride (TG), glutamic oxaloacetic transaminase (AST), glutamic-pyruvic transaminase (ALT), blood urea nitrogen (BUN), creatinine (CR), and hypersensitive C-Reactive Protein (hr-CRP).

\section{Enrichment of medium and low abundance serum proteins}

As type A and type B were more representative than the other subtypes, one sample from each was selected for mass spectrometry analysis. The number of peptides and peptidespectrum matches (PSMs) identified in A1-A15 ranged from 429 to 950 , and 782 to 1,563 , respectively, and the proteins identified by more than two peptides ranged from 48 to 87 in the gel bands of type A and type B (Figure 3A). The sum of the molecular weights of the proteins identified from each band was much larger than the calculated molecular weight 


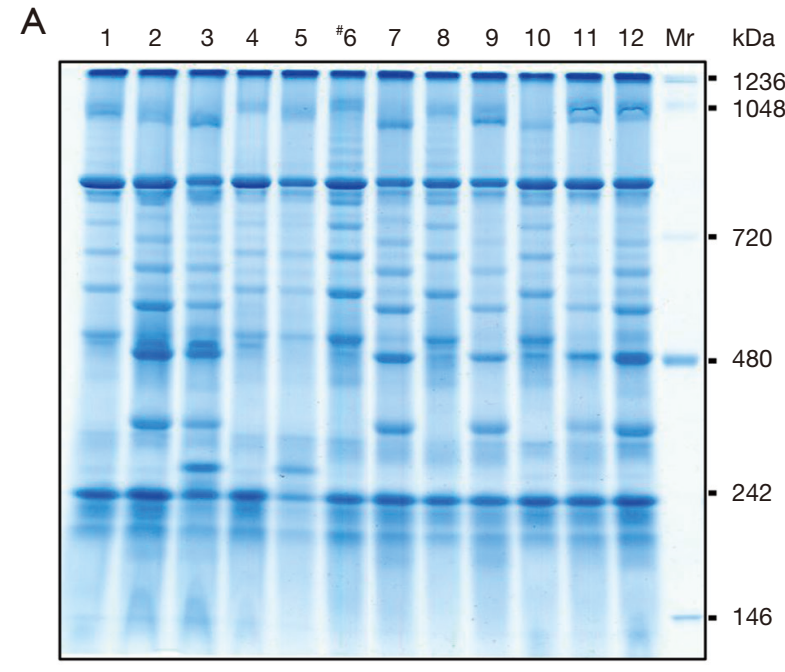

B

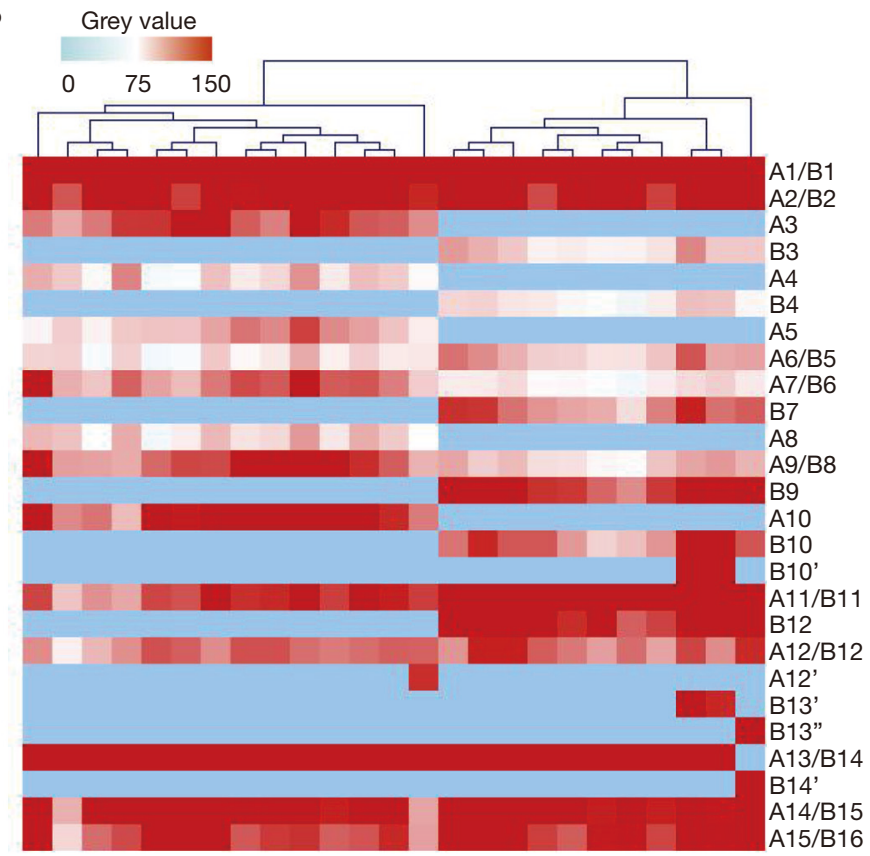

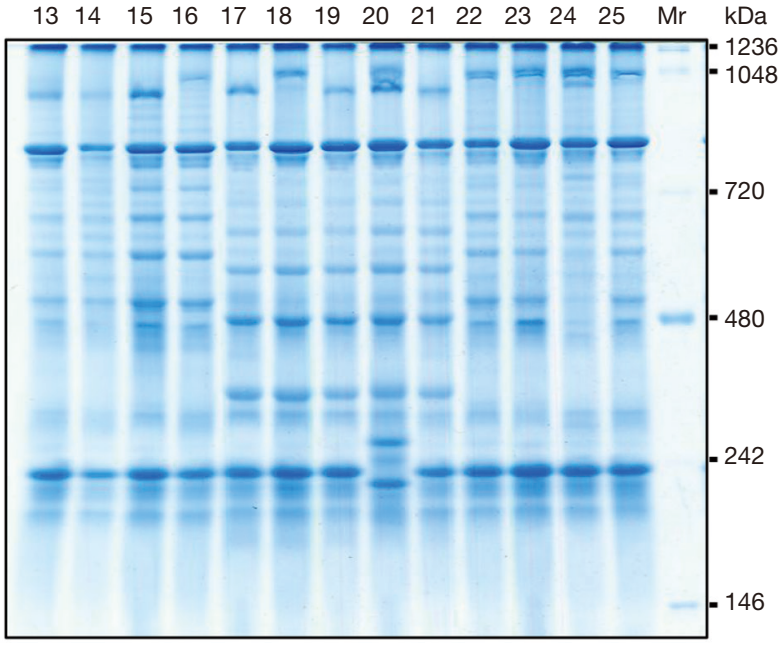

C

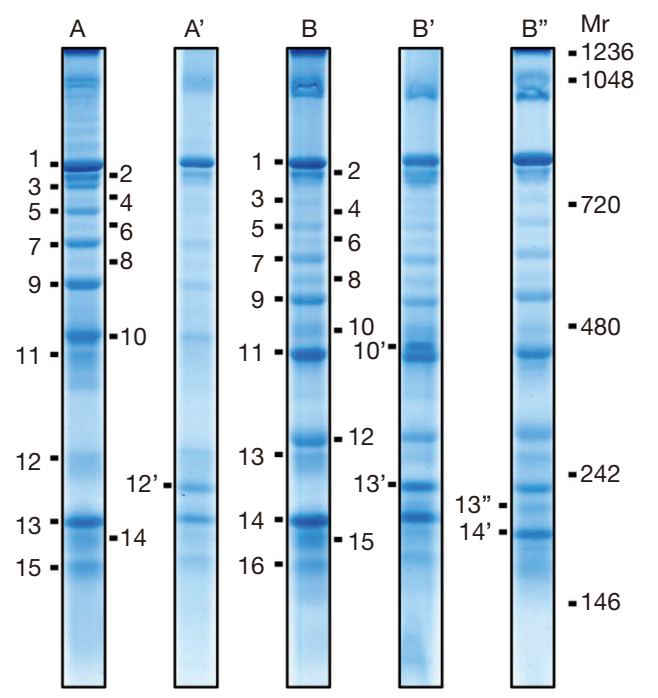

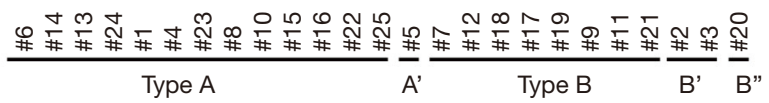

Figure 2 Varied protein complex patterns identified from balanced constitution individuals. (A) The BN-PAGE results of sera from 25 balanced constitutional individuals were significantly heterogeneous. (B) Patterns of gel bands (bands A1-A15 and B1-B16) in sera isolated by BN-PAGE, the position of bands in BN-PAGE was determined by their molecular weight. $\mathrm{Mr}$ and $\mathrm{kDa}$ indicate protein marker and kilodalton, respectively. (C) The clustering was generated according to the gray value and molecular weight, with two major patterns and three minor patterns of 25 people with Balanced TCM constitution. 
A Quality control of database search results for gel bands.

\begin{tabular}{|c|c|c|c|c|c|c|c|c|c|c|c|c|c|c|}
\hline \multirow{2}{*}{$\begin{array}{c}\text { MW } \\
\text { (kDa) } \\
\text { interval }\end{array}$} & \multicolumn{7}{|c|}{ Type A } & \multicolumn{7}{|c|}{ Type B } \\
\hline & $\begin{array}{c}\text { Band } \\
\text { ID }\end{array}$ & $\begin{array}{l}\text { Protein } \\
(\text { pep } \geq 2)\end{array}$ & Peptide & PSM & Pep/Pro & PSM/Pep & $\begin{array}{l}\text { Calculation } \\
\text { of Pro MW }\end{array}$ & $\begin{array}{c}\text { Band } \\
\text { ID }\end{array}$ & $\begin{array}{l}\text { Protein } \\
(\text { pep } \geq 2)\end{array}$ & Peptide & PSM & Pep/Pro & PSM/Pep & $\begin{array}{l}\text { Calculation } \\
\text { of Pro MW }\end{array}$ \\
\hline \multirow{5}{*}{$\begin{array}{l}720- \\
1048\end{array}$} & Al & 48 & 429 & 806 & 8.94 & 1.88 & 3453 & B1 & 56 & 580 & 1001 & 9.67 & 1.73 & 3730 \\
\hline & $\mathrm{A} 2$ & 59 & 602 & 972 & 9.56 & 1.61 & 3576 & $\mathrm{~B} 2$ & 50 & 513 & 889 & 9.68 & 1.72 & 3573 \\
\hline & $\mathrm{A} 3$ & 59 & 528 & 789 & 8.52 & 1.49 & 3380 & B3 & 75 & 654 & 899 & 8.29 & 1.37 & 4636 \\
\hline & A4 & 67 & 548 & 782 & 7.72 & 1.43 & 3638 & B4 & 75 & 677 & 957 & 8.46 & 1.41 & 4294 \\
\hline & A5 & 64 & 581 & 837 & 8.67 & 1.44 & 3519 & B5 & 72 & 675 & 927 & 9.12 & 1.37 & 4348 \\
\hline \multirow{6}{*}{$\begin{array}{c}480- \\
720\end{array}$} & A6 6 & 72 & 644 & 920 & 8.26 & 1.43 & 3982 & B6 & 73 & 662 & 940 & 8.71 & 1.42 & 4471 \\
\hline & A7 & 74 & 558 & 799 & 7.54 & 1.43 & 3881 & B7 & 67 & 682 & 982 & 9.61 & 1.44 & 4334 \\
\hline & A8 & 75 & 709 & 1025 & 9.09 & 1.46 & 4189 & B8 & 82 & 745 & 1118 & 8.76 & 1.50 & 5207 \\
\hline & A9 & 70 & 610 & 889 & 8.36 & 1.46 & 5060 & B9 & 81 & 764 & 1153 & 9.43 & 1.51 & 4701 \\
\hline & A10 & 61 & 540 & 841 & 8.57 & 1.56 & 3687 & B10 & 87 & 752 & 1114 & 8.36 & 1.48 & 5170 \\
\hline & A11 & 81 & 694 & 1117 & 8.36 & 1.61 & 4384 & B11 & 70 & 634 & 1114 & 8.68 & 1.76 & 4362 \\
\hline \multirow{3}{*}{$\begin{array}{c}242- \\
480\end{array}$} & A12 & 84 & 950 & 1563 & 11.31 & 1.65 & 5909 & $\mathrm{~B} 12$ & 73 & 780 & 1204 & 10.68 & 1.54 & 4847 \\
\hline & A13 & 70 & 749 & 1074 & 10.70 & 1.43 & 4377 & B13 & 77 & 862 & 1483 & 11.19 & 1.72 & 5171 \\
\hline & & & & & & & & B14 & 66 & 683 & 947 & 10.35 & 1.39 & 4098 \\
\hline \multirow[b]{2}{*}{$<242$} & A14 & 76 & 822 & 1173 & 10.82 & 1.43 & 4857 & $\mathrm{~B} 15$ & 75 & 795 & 1231 & 10.6 & 1.55 & 4614 \\
\hline & A 15 & 70 & 674 & 995 & 9.63 & 1.48 & 4633 & B16 & 68 & 696 & 1072 & 10.24 & 1.54 & 4317 \\
\hline
\end{tabular}

B
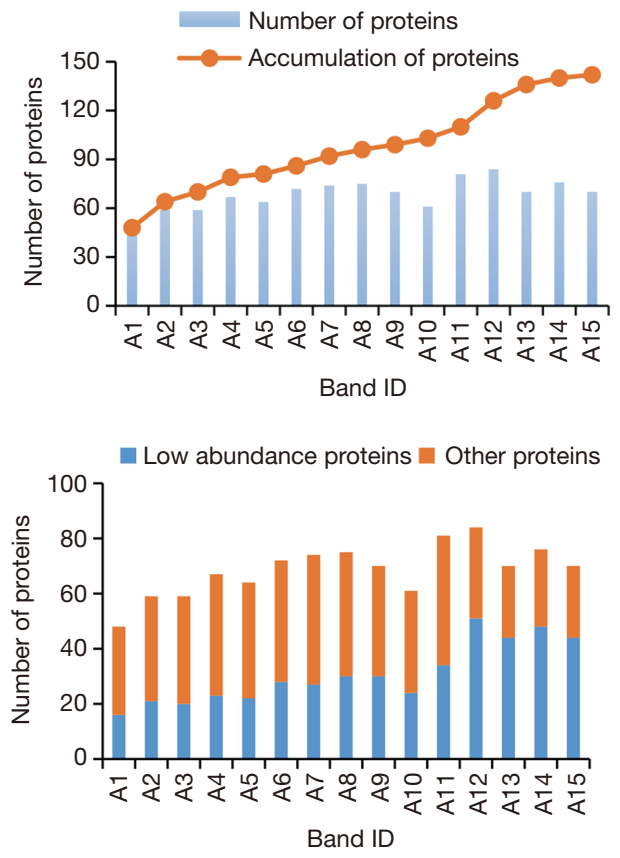

$\mathrm{F}$

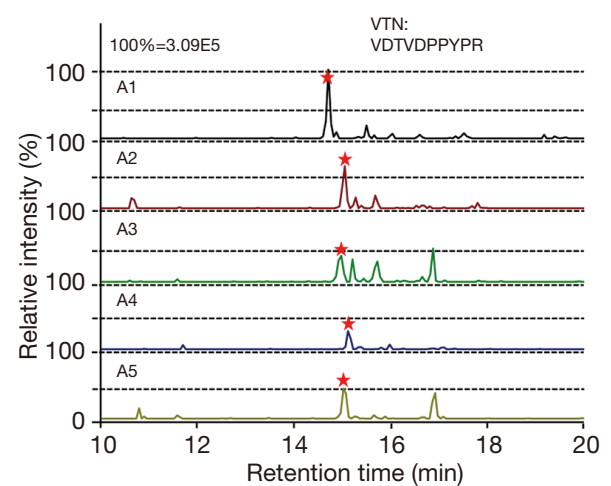

C
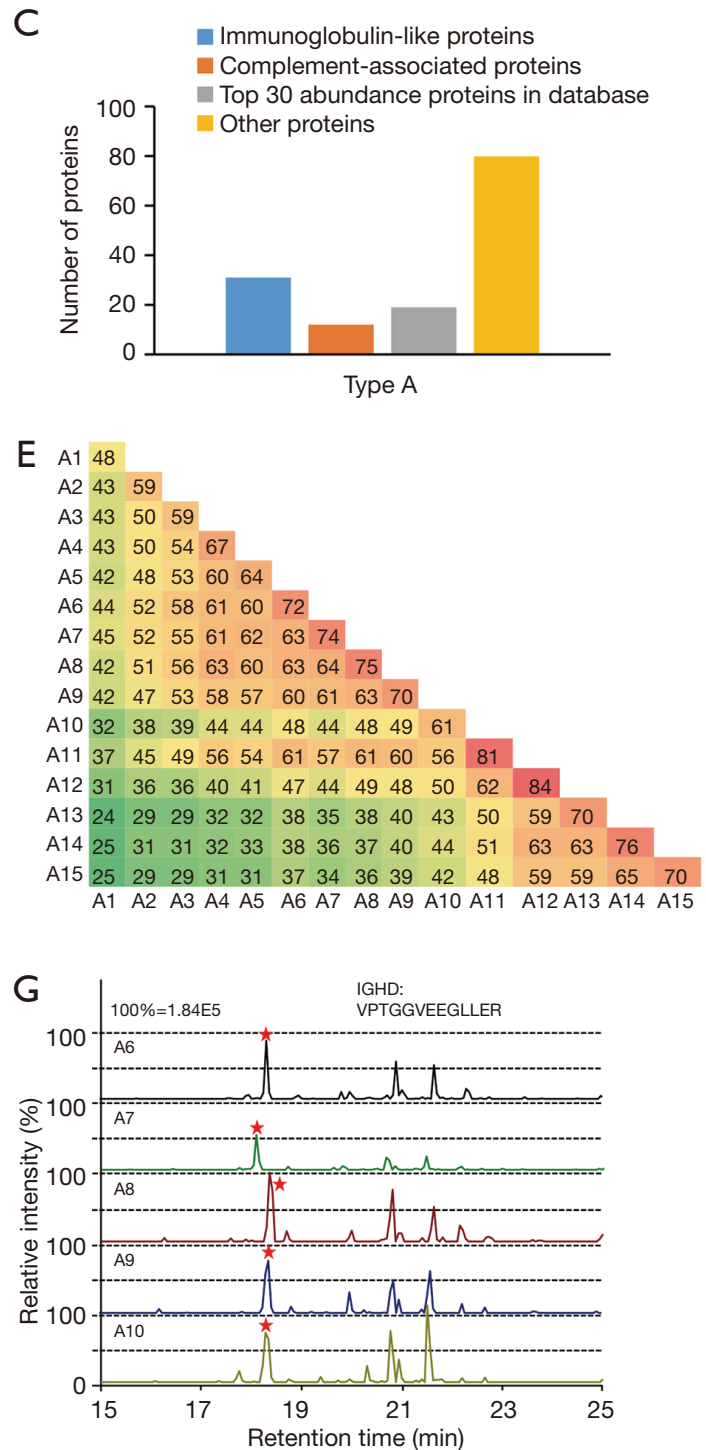


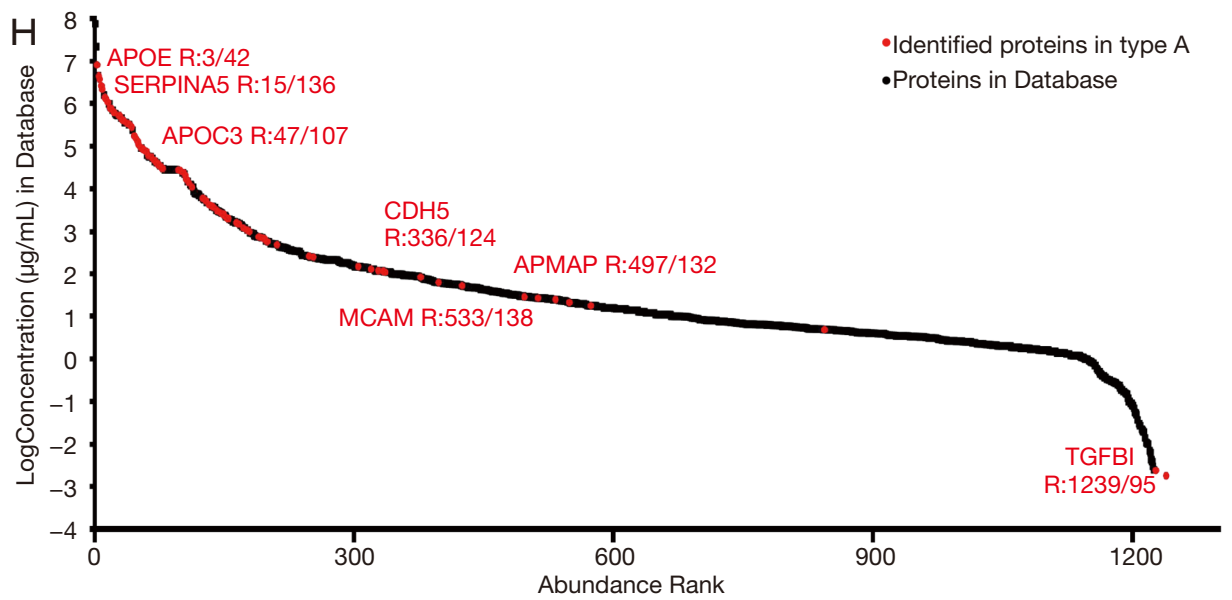

Figure 3 Enrichment of medium and low abundance serum proteins in blue native gel bands. (A) The quality control of database search results for each band of the two types. Quantity of identified proteins, peptides and PSM, the proportion of peptides/proteins and PSM/ peptides, all of which are shown on the table. The molecular weight of bands was not the sum of identified proteins' molecular weight. (B) Count of identified proteins. (C) Number of the four different kinds of proteins in type A, including 31 (29\%) immunoglobulin-like proteins, $12(8 \%)$ complement-associated proteins, $19(13 \%)$ proteins which were in the top 30 most abundant proteins of the plasma database, and 80 (56\%) proteins with medium-to-low abundance. (D) Number of low-abundance proteins and other proteins in bands of type A. (E) Number of overlapped proteins in type A. (F,G) Elution profiles of peptides in type A. Intensity of proteins identified at the same elution stage of different gel bands were different, and components of bands were also different. (H) Abundance and rank of identified proteins in plasma protein database; the rank in the identified proteins did not match the rank in the database. "number/number" represents "the rank in database/the rank in identified proteins".

of any particular protein complex band, which suggested the presence of multiple protein complexes in each individual band. This was also supported by the phenomena of the molecular weights of the gel bands being disproportionate to the number of identified proteins and peptides. In total, 142 proteins were identified in both the 15 bands of type $\mathrm{A}$ and 15 bands of type B (Figure 3B, Figure S1A). In type A, 62 (44\%) proteins were immunoglobulin-like proteins, complement-associated proteins, and the proteins which were the top 30 most abundant proteins in normal serum samples. We also identified 80 (56\%) proteins with a medium-to-low abundance in the serum (Figure 3C). More interestingly, we noticed that almost one-third of these low abundance proteins were identified in multiple bands (Figure 3D), suggesting medium-to-low abundance proteins in serum were enriched in these gel bands.

Comparing the protein lists identified from different gel bands, we found that the number of overlapped proteins ranged from 24 to 65 , which indicated the difference of these identified protein complexes (Figure 3E). As expected, the abundance of the same protein in different bands was varied. For example, protein vitronectin (VTN), a glycoprotein with high abundance in serum (ranked 30th out of 1,239 in database), was present in A1-A5 with an almost identical peak shape in chromatography and ration time $(15 \mathrm{~min})$, and the intensity of VTN was $3.09 \times 10^{5}$ (100\%) which ranked 15 th out of 48 in A1 (Table S2). The least abundant protein was $1.10 \times 10^{5}(36 \%)$ in $\mathrm{A} 4$, and was only one-third of that in A1 (Figure $3 F$ ). This suggested that the high abundance proteins in serum were also enriched in some particular bands, but the abundance ranking of the identified proteins in gel bands was far lower than that in the plasma database (ranked 29th out of 1,240 in database). The protein Ig delta chain C region (IGHD) was not included in the serum protein database but was present in A6-A10 at about $17-18 \mathrm{~min}$ of ration time. Interestingly, the highest intensity of IGHD was $1.84 \times 10^{5}(100 \%)$ in A8. The lowest abundant one was $1.02 \times 10^{5}$ (55\%) in A7, which was only half of that in A8 (Figure $3 G$ ). This result clearly showed that the low abundance proteins in the serum samples also accumulated in the protein complex bands. These results further verified that the approach we applied 
in this study may be helpful in exploring some of the serum proteins that reflected the characteristics of the human population.

We also compared the abundance of the 142 proteins identified from the type A and type B protein complexes with those in the plasma protein database (http://www. plasmaproteomedatabase.org/). Surprisingly, 28 proteins identified in one sample of the type A were not present in the plasma protein database. These newly identified proteins from the isolated protein complexes on the $\mathrm{BN}$ gel strongly supported the specificity of the method we applied here. Among the top 200 abundant proteins in the plasma database (31), 94 proteins were also identified from our protein complex samples isolated from the $\mathrm{BN}$ gel. The remaining 20 proteins were medium-tolow abundance proteins in serum samples. However, the ranking of the protein abundance in our samples was not consistent with that in the plasma proteome database. For example, apolipoprotein E (APOE), one of the most abundant proteins in the plasma database, was ranked as the 42nd most abundant protein in the 142 proteins identified in type A. Plasma serine protease inhibitor (SERPINA5), which was ranked as the 15 th most abundant proteins in the plasma database, was ranked 136th out of 142 in our proteins (Figure 3H). The details of the protein abundance comparison between type $\mathrm{B}$ and the plasma database are shown in Figure S1B.

\section{Commonality and specificity of different protein complex patterns at the protein level}

About 10 pairs of bands existed in both type A and type B of the balanced constitution samples with the same molecular weight and size, including $\mathrm{A} 1$ and $\mathrm{B} 1, \mathrm{~A} 2$ and $\mathrm{B} 2, \mathrm{~A} 6$ and $\mathrm{B} 5, \mathrm{~A} 7$ and $\mathrm{B} 6, \mathrm{~A} 9$ and $\mathrm{B} 8, \mathrm{~A} 11$ and $\mathrm{B} 11, \mathrm{~A} 12$ and $\mathrm{B} 12, \mathrm{~A} 13$ and B14, A14 and B15, and A15 and B16 (Figure 2B). The percentage of the overlapped proteins in these paired bands was $>58 \%$ (Figure $4 A$ ). Although some unique proteins might not have existed at the same molecular weight in the paired bands, they were also identified at different molecular weights of the bands. Meanwhile, some unique proteins existed in only one sample but not the other. This further proved the specificity of the band and the difference between type A and type B were due to biological differences. The proteins identified in type A and B serum samples were compared. In total, 124 proteins were found in both of these datasets, with 18 unique proteins present in type $\mathrm{A}$ but not in $\mathrm{B}$, and another 18 unique proteins identified in type B but not in type A (Figure 4B). GO analysis showed that the unique proteins in type A were involved mainly in lipid metabolic processes, while the unique proteins in type $B$ were involved in the immune response and inflammatory response pathways (Figure 4C). Cellular components of the unique proteins in type A and type B both existed in extracellular regions (Figure 4D). The molecular function of the unique proteins in type A might be lipoprotein activity, while that of the unique proteins in type $\mathrm{B}$ might be endopeptidase activity and antigen binding (Figure 4E).

The TCM transformation scores of type A and type B were evaluated using the TCM Constitution Scale. The TCM convert score of qi-deficiency in the type A population was significantly higher than that in the type B population, while the transformation score of dampheat constitution in the type B population was significantly higher than that in the type A population (Figure 4F). This result indicated that the classification of Balanced constitutional population based on the protein complex pattern may be associated with the transformation score of TCM constitution. There might not be clear-cut boundaries between the human TCM constitution types. People with Balanced constitution of type A may have a tendency towards a qi-deficiency constitution, while people with balanced constitution of type B may share some characteristics of a damp-heat constitution. This study provided us with a reference to reclassify the balanced constitutional population based on the protein profile.

\section{Discussion}

TCM constitution should be considered as an approach to describe the state of human health. However, Balanced constitution does not necessarily equate to a healthy state. People with balanced constitutions can also get sick, and the development of disease depends on the particular tendency of each balanced constitution. Therefore, research involving the balanced constitution needs to be taken seriously (32).

The current classification and determination of TCM constitution is mainly determined by a score which is based on the exclusion questions, making the balanced constitution more akin to a hybrid of the constitutions which could not be classified to any other specific unbalanced constitution (33). Our study explored the protein complex patterns of people with a TCM balanced constitution and their associations with unbalanced constitution convert scores. This is the first investigation 
A $\quad$ A1
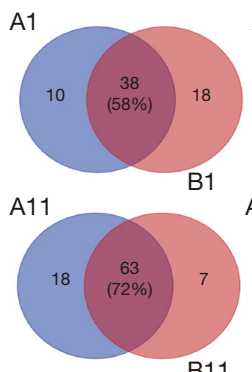

B11
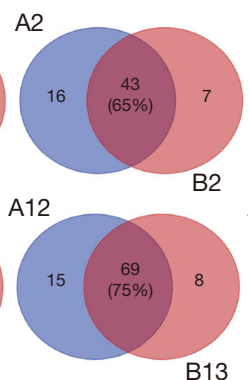

B

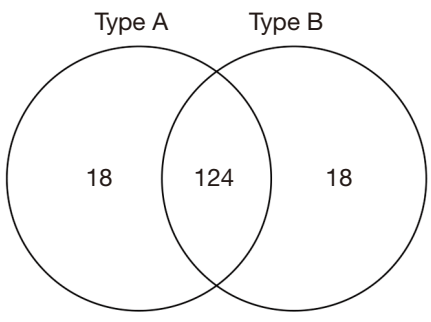

D

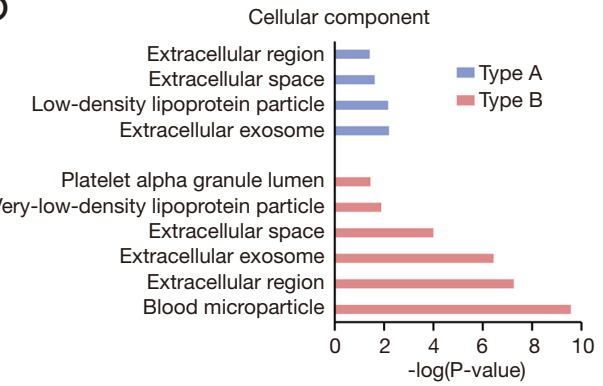

$\mathrm{F}$

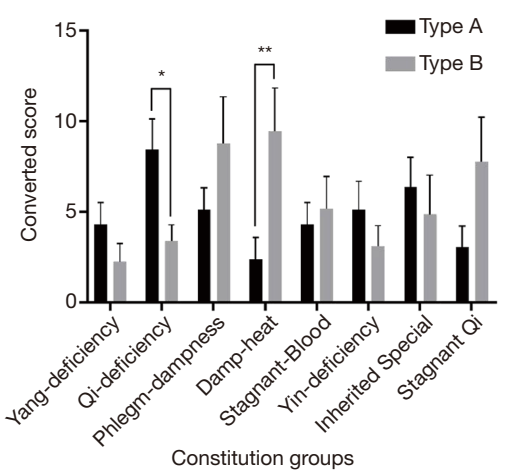

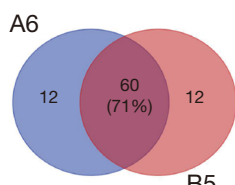
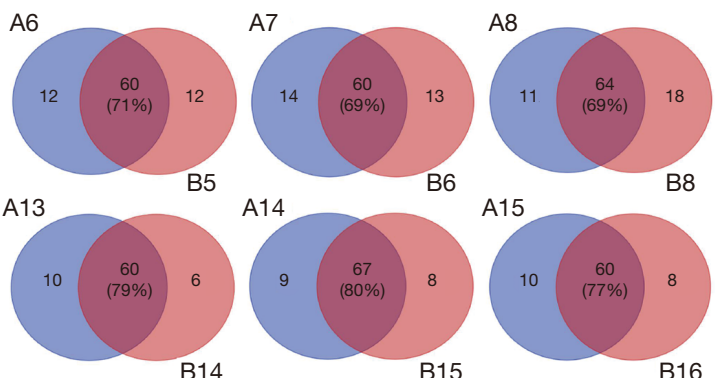

B15

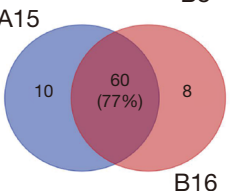

C

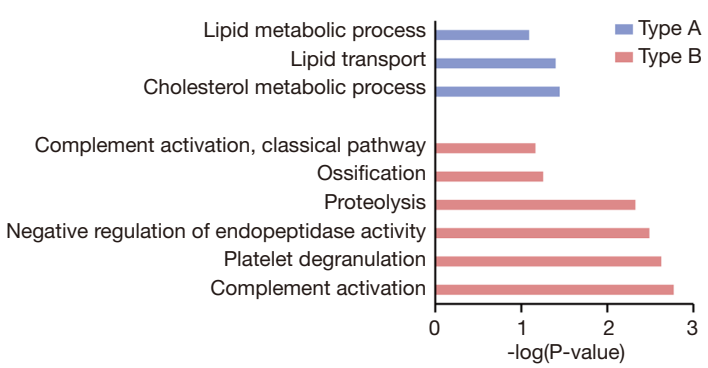

$\mathrm{E}$

Molecular function

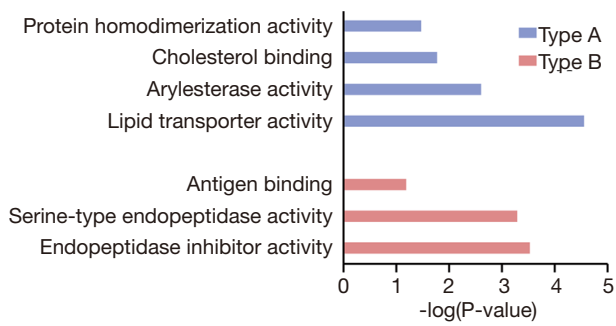

Figure 4 Different protein complex patterns have commonalities and specificities at the protein level, which are related to the unbalanced constitution convert score. (A) The overlap of identified proteins at the same molecular weight position but in different protein complex patterns. (B) The overlap of the proteins identified by type A and type B was 124, and the sum of identified proteins of all bands in type A and type B was 142. (C) Biological pathway enrichment analysis based on unique proteins of type A and type B. (D) Cellular component enrichment analysis of unique proteins belonging to type A and type B. (E) Molecular function enrichment analysis of unique proteins belonging to type A and type B. The vertical axis is the pathway category, and the horizontal axis is the $\log \mathrm{P}$ value of the pathway. (F) The unbalanced constitution convert scores of 25 balanced constitutional people; the difference of qi-deficiency score and damp-heat score between people of type A and type B was statistically significant. Unpaired $t$-test, ${ }^{*}, \mathrm{P}<0.05,{ }^{* *}, \mathrm{P}<0.01$. 
into the classification of the balanced constitution to study their innate characteristics using serum proteomics.

Some clinical studies have shown that there were significant differences in the pulse patterns among different constitutions and the balanced constitution normally exhibited gentle and slow pulses (34-37). The study of protein complexes in blood can enrich the modern scientific connotation of TCM pulse diagnosis and construct a more complete and objective TCM constitution theory. In the serum proteomics studies conducted by other groups, a commercial affinity removal column was used to remove high abundance proteins from the serum, which is convenient but costly. In another study, serum was denatured by denaturants $(38,39)$, which resulted in the natural state of the serum proteins being insufficiently maintained. In our study, BN-PAGE reduced the percentage of high-abundance proteins but specifically enriched medium-to-low abundance proteins in serum, which was low-cost and easy to operate. The people with balanced constitutions were categorized according to their protein complex patterns. BN-PAGE-based serum protein complex analysis identified two stable and reproducible types of protein complex patterns for the balanced constitution population, which provided a new method for the classification of TCM constitution.

The significance of TCM constitution research is related to preventive treatment, which focuses on adjusting the balance of the immune system and metabolism (40). When changes to the internal and external environment result in imbalance of the immune system or metabolic disorder $(41,42)$, the balanced constitution tends to become unbalanced. People with the qi-deficiency constitution always have abnormal energy metabolism, in which lipid metabolism is important $(43,44)$. In this study, people of the type Balanced constitution had a higher qi-deficiency convert score, and the unique proteins of type A were enriched in the pathways related to lipid metabolism, suggesting that people of type A may be at risk of metabolic diseases. This result is consistent with previous reports that the proportion of obesity, diabetes, and hypertension in the people with qi-deficiency constitutions is higher than that in healthy people $(45,46)$. Damp-heat is a pathogenic factor in traditional Chinese medicine, and is closely related to immune dysfunction of the body (47). The gene expression in people with the damp-heat constitution exhibits an abnormally high immune response, which can manifest as various diseases. The appropriate TCM treatment of this type starts by reducing the body's inflammatory response and restoring the dynamic balance of the immune system (48-50). The type B population had a higher damp-heat constitution score, and its unique proteins were enriched in immune- and inflammation-related biological pathways, which indicates the association between type $B$ and the damp-heat constitution. Immune regulation, inflammatory response, and lipid metabolism may be the potential mechanisms for the individual differences among people with Balanced constitution.

\section{Conclusions}

In summary, BN-PAGE is a robust method to isolate protein complexes in serum, and the use of BN-PAGE followed by LC-MS/MS technology is effective to establish the serum protein complex profile. Our study was the first to provide insight into the association of protein complex patterns with individual differences among the TCM balanced constitution population, and verifies some common characteristics between the balanced and unbalanced constitution types. This novel serum proteomic profile, which used protein complexes as indicators of physical status, can help TCM professionals to identify the characteristics of people with the balanced constitution, thus providing a direction for increasingly targeted therapies for the different TCM constitutions.

\section{Acknowledgments}

Funding: This work was supported by the Chinese National Basic Research Programs (no. 2017YFC0906600 and 2017YFD0501500), the Foundation of Guangdong Provincial Hospital of Traditional Chinese Medicine (no. YN2018DB02, YN2018RBA01, and 2016KT1206), the National Natural Science Foundation of China (no. 31670834, 31700723, 31870824, 31901037, and 91839302), the Chinese National Key Project Specialized for Infectious Diseases (no. 2018ZX10302302), the Guangzhou Science and Technology Innovation \& Development Project (no. 201802020016), and the Foundation of State Key Lab of Proteomics (no. SKLP-K201704).

\section{Footnote}

Peer Review File: Available at http://dx.doi.org/10.21037/ apm-20-290

Data Sharing Statement: Available at http://dx.doi. 
org/10.21037/apm-20-290

Conflicts of Interest: All authors have completed the ICMJE uniform disclosure form (available at http://dx.doi. org/10.21037/apm-20-290). The authors have no conflicts of interest to declare.

Ethical Statement: The authors are accountable for all aspects of the work in ensuring that questions related to the accuracy or integrity of any part of the work are appropriately investigated and resolved. The study was approved by the Animal Ethics Committee of Guangdong Provincial Hospital of Chinese Medicine (B2017-150-01) and performed in accordance with the Declaration of Helsinki (as revised in 2013). Informed consent was given by all participants.

Open Access Statement: This is an Open Access article distributed in accordance with the Creative Commons Attribution-NonCommercial-NoDerivs 4.0 International License (CC BY-NC-ND 4.0), which permits the noncommercial replication and distribution of the article with the strict proviso that no changes or edits are made and the original work is properly cited (including links to both the formal publication through the relevant DOI and the license). See: https://creativecommons.org/licenses/by-nc-nd/4.0/.

\section{References}

1. Buss DM. How can evolutionary psychology successfully explain personality and individual differences? Perspect Psychol Sci 2009;4:359-66.

2. John OP, Gross JJ. Healthy and unhealthy emotion regulation: personality processes, individual differences, and life span development. J Pers 2004;72:1301-33.

3. Wang J, Li YS, Ni C, et al. Cognition research and constitutional classification in Chinese medicine. Am J Chin Med 2011;39:651-60.

4. Wang Q. Classification and determination of constitution in TCM. Beijing: China Press of Traditional Chinese Medicine, 2009.

5. Wang Q. Constitutional doctrine of traditional Chinese medicine. Beijing: People's Medical Publishing House, 2008.

6. Zhang HM, Wang J. Study on the pathogenesis of diseases caused by biased constitution from the gene-environment interaction. China Journal of Traditional Chinese Medicine and Pharmacy 2015;30:3580-2.
7. Li LR, Wang J, Li YS, et al. Basic research status of syndromes and diseases of TCM and the necessity of introducing dimension of TCM constitution. China Journal of Traditional Chinese Medicine and Pharmacy 2017;32:2347-9.

8. Wang QF, Wang QB, Wang Q. Guidance of TCM constitution theory on disease prevention. Liaoning Journal of Traditional Chinese Medicine 1993;3:15-8.

9. Dong LP. Association of TCM constitution theory and disease. Chinese Journal of Basic Medicine in Traditional Chinese Medicine 2006;12:859-60.

10. Liu J. The theory of constitution of traditional Chinese medicine and the treatment of diseases. Chinese Journal of Basic Medicine in Traditional Chinese Medicine 2009;15:316-7.

11. Zhou LY, Liu J, Zhang JQ, et al. Reflection on the balanced constitution and its identification method. China Medical Herald 2016;13:62-5.

12. Dong J, Duan MM, Wang K. Investigation of TCM constitutions and psychological status of tumor patients. Journal of Qilu Nursing 2015;21:53-4.

13. Zhai F, Gao H. Application of traditional chinese medicine constitution identification in health management of chronic diabetes patients. J Clin Med Pract 2018;22:62-5.

14. Zhu L, Liu LG. Research of traditional Chinese medicine constitutions in diabetes mellitus patients. J Exp Clin Med 2015;14:1311-3.

15. Han SH, Kong XD, Song LX, et al. Correlation analysis of traditional Chinese medicine constitution types and rheumatoid arthritis. Liaoning Journal of Traditional Chinese Medicine 2017;19:192-5.

16. Yang XY, Zhang LK, Sheng L, et al. Relationship between anxiety, depression, and TCM constitution. Chinese Journal of Integrative Medicine on Cardio-/ Cerebrovascular Disease 2017;15:1903-1905.

17. Yang X, Li XZ, Fu NN, et al. Effect of acupuncture for pain threshold among the groups of different constitutions. Chinese Acupuncture \& Moxibustion 2016;36:491-5.

18. Wang Q, Tan YQ. Research on relativity of the propagated sensation along meridian and traditional Chinese medicine constitution of middle-aged person. China Journal of Traditional Chinese Medicine and Pharmacy 2017;32:1811-5.

19. Issaq HJ, Xiao Z, Veenstra TD. Serum and plasma proteomics. Chem Rev 2007;107:3601-20.

20. Wu HK, Ko YS, Lind YS, et al. The correlation between pulse diagnosis and constitution identification in traditional Chinese medicine. Complement Ther 
Med 2017;30:107-12.

21. Tsai YN, Chang YH, Huang YC, et al. The use of timedomain analysis on the choice of measurement location for pulse diagnosis research. J Chin Med Assoc 2019;82:78-85.

22. Ray S, Reddy PJ, Jain R, et al. Proteomic technologies for the identification of disease biomarkers in serum: advances and challenges ahead. Proteomics 2011;11:2139-61.

23. Ioannidis JP, Panagiotou OA. Comparison of effect sizes associated with biomarkers reported in highly cited individual articles and in subsequent meta-analyses. JAMA 2011;305:2200-10.

24. Hartwell LH, Hopfield JJ, Leibler S, et al. From molecular to modular cell biology. Nature 1999;402:C47-C52.

25. Wittig I, Braun HP, Schagger H. Blue native PAGE. Nat Protoc 2006;1:418-28.

26. Yang J, Yang LC, Li BX, et al. iTRAQ-based proteomics identification of serum biomarkers of two chronic hepatitis B subtypes diagnosed by traditional Chinese medicine. Biomed Res Int 2016;2016:3290260.

27. Xu M, Deng JW, Xu KK, et al. In-depth serum proteomics reveals biomarkers of psoriasis severity and response to traditional Chinese medicine. Theranostics 2019;9:2475-88.

28. Xu P, Duong DW, Seyfried NT, et al. Quantitative proteomics reveals the function of unconventional ubiquitin chains in proteasomal degradation. Cell 2009;137:133-45.

29. Huang W, Sherman BT, Lempicki RA. Bioinformatics enrichment tools: paths toward the comprehensive functional analysis of large gene lists. Nucleic Acids Res 2009;37:1-13.

30. Huang W, Sherman BT, Lempicki RA. Systematic and integrative analysis of large gene lists using DAVID bioinformatics resources. Nat Protoc 2009;4:44-57.

31. Anderson NL, Anderson NG. The human plasma proteome: history, character, and diagnostic prospects. Mol Cell Proteomics 2002;1:845-67.

32. Zhu Y, Shi H, Wang Q, et al. Association between nine types of TCM constitution and five chronic diseases: a correspondence analysis based on a sample of 2,660 participants. Evid Based Complement Alternat Med 2017;2017:9439682.

33. Xin H, Wu JK, Guo X, et al. Discussion on the problems of nine traditional Chinese medicine constitutional types scale in clinical application. China Journal of Traditional Chinese Medicine and Pharmacy 2014;29:1841-3.

34. Wang Q. Discussion on the methodology of TCM constitution research. Global Traditional Chinese
Medicine 2010;3:295-7.

35. Zhou GZ, Zhang QC. Investigation of key factors in TCM constitution assessment. Jilin Journal of Traditional Chinese Medicine 2011;31:291-2.

36. Liu HH. TCM constitution identification of five elements in TCM. Hubei Journal of Traditional Chinese Medicine 2015;37:36-8.

37. Chen YK, Liu Q, Qu HY, et al. Study on characteristics of radial artery pulse diagnositic information among healthy people with Qi-deficiency constitution. Journal of Hunan University of Chinese Medicine 2018;38:289-91.

38. Petricoin EF, Liotta LA. SELDI-TOF-based serum proteomic pattern diagnostics for early detection of cancer. Curr Opin Biotechnol 2004;15:24-30.

39. Cho WC, Yip TT, Yip C, Yip V, Thulasiraman V, Ngan RK, Yip TT, Lau WH, Au JS, Law SC, Cheng WW, $\mathrm{Ma} \mathrm{VW}$, et al. Identification of serum amyloid a protein as a potentially useful biomarker to monitor relapse of nasopharyngeal cancer by serum proteomic profiling. Clin Cancer Res 2004;10:43-52.

40. Cheng N, Li YS, Wang Q. Review and prospect of traditional Chinese medicine constitution research for 40 years. Tianjin Journal of Traditional Chinese Medicine 2019;2:108-11.

41. Han XJ, Zhang GQ. Thoughts on the direction of moxibustion development. Journal of Practical Traditional Chinese Internal Medicine 2017;31:69-71.

42. Xu QL, Li YF, Jiang SQ, et al. Discussing the following the prognosis of a disease theory application and the problems in modern medicine. Journal of Henan University of Chinese Medicine 2010;25:74-76.

43. Bi JL, Yan MH, Chen JY, et al. PIasma metabonomic analysis of healthy qi-deficiency constitution afte rthe intervention by Buzhongyiqi pills. Journal of Chongqing Medical University 2014;38:1124-7.

44. Bi JL, Chen JY, Cheng JR, et al. The comparative plasma metabonomic analysis of Qi-deficiency constitution and gentleness constitution. J Trop Med 2014;14:717-20.

45. Luo H, Li LR, Wang Q. Correlation between qi deficiency constitution and disease: a bibliometric analysis of 332 observational studies. Tianjin Journal of Traditional Chinese Medicine 2019;36:625-30.

46. Yu RX, Li YS, Wang Q Three problems of traditional Chinese medicine intervention of obese people. China Journal of Traditional Chinese Medicine and Pharmacy 2016;31:3601-3.

47. Zhou SS, Lu XJ, Feng LC, et al. Screening of differentially expressed genes and their functions in Damp-heat 
constitution of Chinese medicine. Liaoning Journal of Traditional Chinese Medicine 2017;44:1819-23.

48. Guo JC, Lin J, Xin L, et al. The influence of traditional Chinese medicine for invigorating the spleen on the immune inflammation of rheumatoid arthritis patients with dampness heat Bi obstruction based on association rules. Lishizhen Medicine and Materia Medica Research 2017;28:1002-4.

49. Miao B, Wang HQ, Zheng SQ. Effect of changing

Cite this article as: Tan F, Zhang T, Chen X, Song T, Yuan J, Sun C, Xu F, Li Y, Chang L, Wang F, Shao C, Zhu W, Xu P, Yang Z. Serum protein complex profiling reveals heterogeneity of Balanced constitutional population in traditional Chinese medicine through blue native polyacrylamide gel electrophoresis. Ann Palliat Med 2021;10(2):1703-1716. doi: 10.21037/apm-20-290 decoction on immune function, cyto inflammatory factor and intestinal flora in acute ulcerative colitis rats of Dampheat type. Journal of Emergency in Traditional Chinese Medicine 2019;28:1747-50.

50. Zhang NN, Cui C, Zhang ZW. Effect of Zaoshihewei formula on HPA axis, inflammatory factors and immune function in rats with dampness heat syndrome of spleen and stomach. Chinese Journal of Modern Applied Pharmacy 2019;36:1633-8. 


\section{Supplementary}

Table S1 Demographic Data of individuals belonging to type A or type B.

\begin{tabular}{|c|c|c|c|c|}
\hline Group & & Type A & Type B & ${ }^{*} \mathrm{P}$-value \\
\hline Age & (year) & $50.64 \pm 11.882$ & $53.64 \pm 8.298$ & 0.485 \\
\hline BMI & $\left(\mathrm{kg} / \mathrm{m}^{2}\right)$ & $24.25 \pm 2.748$ & $26.32 \pm 2.64$ & 0.069 \\
\hline HR & (beats/min) & $76 \pm 11.06$ & $80.8 \pm 10.08$ & 0.296 \\
\hline DBP & $(\mathrm{mmHg})$ & $65.71 \pm 13.11$ & $68.18 \pm 15.56$ & 0.671 \\
\hline FPG & $(\mathrm{mmol} / \mathrm{L})$ & $4.19 \pm 0.52$ & $4.71 \pm 1.13$ & 0.178 \\
\hline TC & $(\mathrm{mmol} / \mathrm{L})$ & $6.21 \pm 1.33$ & $6.53 \pm 1.78$ & 0.607 \\
\hline TG & $(\mathrm{mmol} / \mathrm{L})$ & $1.48 \pm 0.67$ & $2.07 \pm 1.06$ & 0.103 \\
\hline BUN & $(\mathrm{mmol} / \mathrm{L})$ & $5.82 \pm 3.661$ & $5.42 \pm 0.8$ & 0.727 \\
\hline CR & $(\mu \mathrm{mol} / \mathrm{L})$ & $87.64 \pm 52.877$ & $71 \pm 14.744$ & 0.323 \\
\hline $\mathrm{Hb}$ & (mg/L) & $139.36 \pm 15.95$ & $139.18 \pm 12.87$ & 0.977 \\
\hline hr-CRP & (\%) & $1.93 \pm 2.24$ & $1.53 \pm 1.29$ & 0.580 \\
\hline
\end{tabular}

BMI-Body mass index, HR-Heart rate, SBP-Systolic blood pressure, DBP-Diastolic blood pressure, FGP-Fasting plasma glucose, TCTotal cholesterol, TG-Total triglyceride, AST-Glutamic oxaloacetic transaminase, ALT-Glutamic-pyruvic transaminase, BUN-Blood urea nitrogen, CR-Creatinine, hr-CRP-Hypersensitive. *P-values were calculated using Student's t-test and Fisher's exact test for continuous and categorical variables, respectively. 

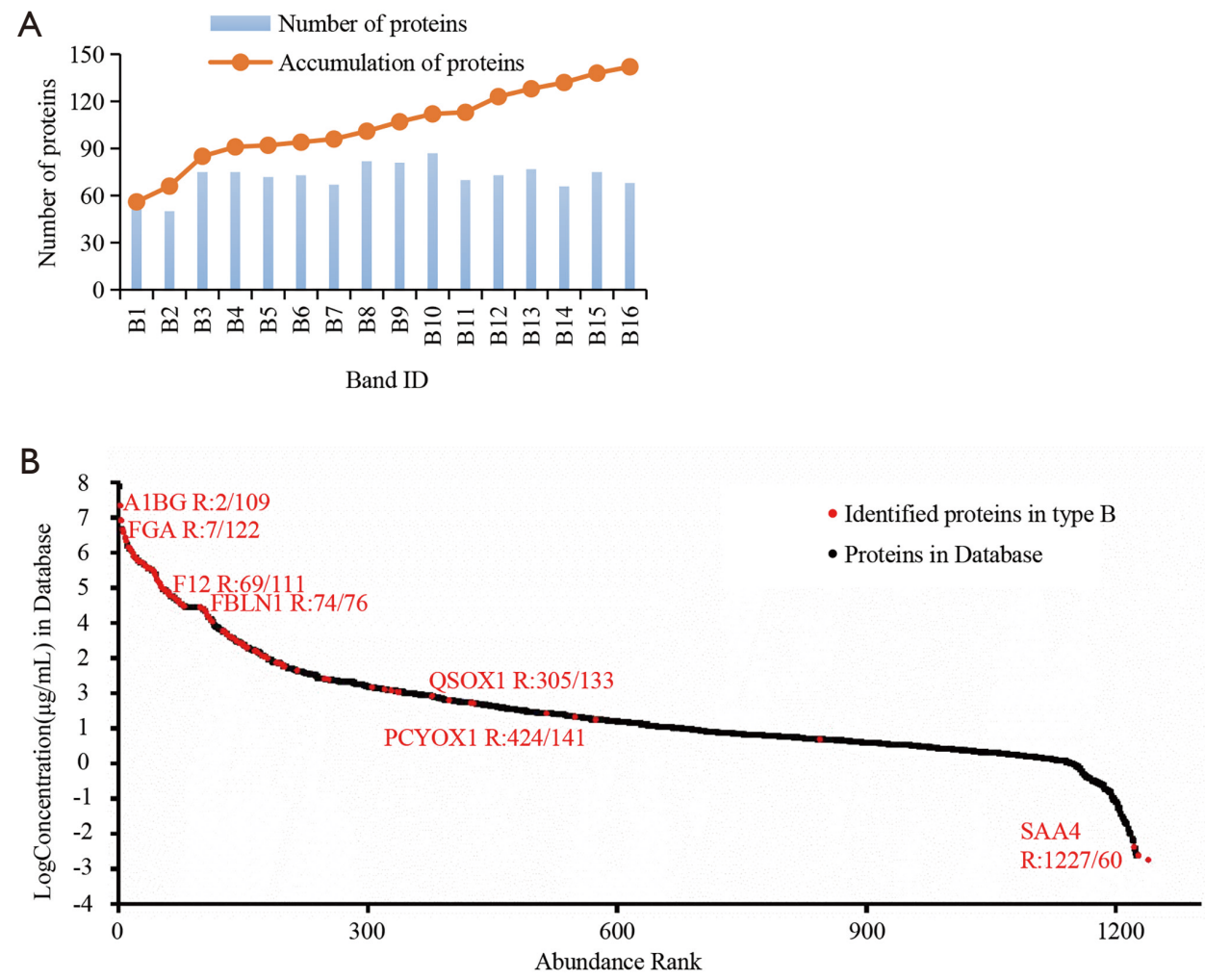

Figure S1 Identified proteins of gel bands in type B. (A) Count of identified proteins number in type B. (B) Abundance and rank of identified proteins in plasma protein database; the rank in identified proteins of type B did not match the rank in the database. "number/ number" represents "the rank in database/ the rank among identified proteins". 


\begin{tabular}{|c|c|c|c|c|c|c|}
\hline Majority protein IDs & Gene names & Sum of proteins & Peptides & Mol. weight [kDa] & iBAQ intensity of $\mathrm{A} 1$ & Rank \\
\hline P01023 & $\mathrm{A} 2 \mathrm{M}$ & 2 & 66 & 163.29 & 86393000 & 1 \\
\hline P01834 & IGKC & 1 & 5 & 11.609 & 48734000 & 2 \\
\hline P00738 & HP & 1 & 20 & 45.205 & 21848000 & 3 \\
\hline P01857 & IGHG1 & 1 & 10 & 36.105 & 13842000 & 4 \\
\hline POCG05 & IGLC2 & 3 & 5 & 11.293 & 9778800 & 5 \\
\hline B9A064 & IGLL5 & 2 & 6 & 23.063 & 4266700 & 6 \\
\hline P01859 & IGHG2 & 1 & 7 & 35.9 & 3143800 & 7 \\
\hline P06312 & IGKV4-1 & 1 & 3 & 13.38 & 2376000 & 8 \\
\hline P01861 & IGHG4 & 1 & 7 & 35.94 & 1981900 & 9 \\
\hline P69905 & HBA1 & 1 & 9 & 15.257 & 1301000 & 10 \\
\hline P01780 & IGLV1-04 & 7 & 3 & 12.943 & 1213000 & 11 \\
\hline P01024 & C3 & 2 & 114 & 187.15 & 920810 & 12 \\
\hline POCOL5 & C4B & 1 & 71 & 192.75 & 797290 & 13 \\
\hline AOAOAOMRZ8 & IGKV3D-11 & 2 & 3 & 12.625 & 555530 & 14 \\
\hline P04004 & VTN & 2 & 7 & 54.305 & 505740 & 15 \\
\hline P01591 & IGJ & 1 & 3 & 18.098 & 364080 & 16 \\
\hline AOA0B4J1VO & IGHV3-15 & 1 & 3 & 12.926 & 278860 & 17 \\
\hline P01602 & IGKV1-5 & 1 & 2 & 12.781 & 266080 & 18 \\
\hline P00734 & F2 & 2 & 8 & 70.036 & 235370 & 19 \\
\hline P02751 & FN1 & 1 & 56 & 262.62 & 219040 & 20 \\
\hline A0A0B4J1U7 & IGHV6-1 & 1 & 3 & 13.481 & 205340 & 21 \\
\hline A0A075B6I0 & IGLV8-61 & 1 & 2 & 12.814 & 190320 & 22 \\
\hline O75636 & FCN3 & 1 & 7 & 32.903 & 157660 & 23 \\
\hline P01009 & SERPINA1 & 2 & 32 & 46.736 & 155780 & 24 \\
\hline AOAOC4DH38 & IGHV5-51 & 1 & 3 & 12.674 & 153800 & 25 \\
\hline P02749 & $\mathrm{APOH}$ & 2 & 3 & 38.298 & 134190 & 26 \\
\hline P08603 & $\mathrm{CFH}$ & 3 & 22 & 139.09 & 131880 & 27 \\
\hline P02647 & APOA1 & 2 & 30 & 30.777 & 97973 & 28 \\
\hline P10909 & CLU & 1 & 18 & 52.494 & 79190 & 29 \\
\hline P05155 & SERPING1 & 2 & 18 & 55.154 & 73172 & 30 \\
\hline P19823 & $\mathrm{ITIH} 2$ & 2 & 34 & 106.46 & 69491 & 31 \\
\hline P01871 & IGHM & 2 & 11 & 49.306 & 66927 & 32 \\
\hline P03952 & KLKB1 & 1 & 13 & 71.369 & 65291 & 33 \\
\hline P07358 & $\mathrm{C} 8 \mathrm{~B}$ & 1 & 13 & 67.046 & 60188 & 34 \\
\hline P05546 & SERPIND1 & 2 & 19 & 57.07 & 58028 & 35 \\
\hline P02671 & FGA & 1 & 6 & 94.972 & 50972 & 36 \\
\hline P06396 & GSN & 3 & 29 & 85.696 & 49794 & 37 \\
\hline P02760 & AMBP & 1 & 5 & 38.999 & 47728 & 38 \\
\hline P02649 & APOE & 2 & 18 & 36.154 & 46160 & 39 \\
\hline Q14624 & $\mathrm{ITIH} 4$ & 2 & 40 & 103.36 & 42648 & 40 \\
\hline P19827 & $\mathrm{ITIH} 1$ & 2 & 30 & 101.39 & 31432 & 41 \\
\hline P09871 & C1S & 1 & 11 & 76.684 & 24459 & 42 \\
\hline P01008 & SERPINC1 & 2 & 6 & 52.602 & 21776 & 43 \\
\hline P01031 & C5 & 2 & 70 & 188.3 & 20816 & 44 \\
\hline P00747 & PLG & 4 & 12 & 90.568 & 18712 & 45 \\
\hline P04114 & APOB & 2 & 216 & 515.6 & 18466 & 46 \\
\hline P06727 & APOA4 & 1 & 14 & 45.398 & 3542 & 47 \\
\hline P02652 & APOA2 & 1 & 5 & 11.175 & 0 & 48 \\
\hline
\end{tabular}

